\title{
Broadening of Cortical Inhibition Mediates Developmental Sharpening of Orientation Selectivity
}

\author{
Ya-tang Li, ${ }^{1,4}$ Wen-pei Ma, ${ }^{1}$ Chen-jie Pan, ${ }^{1,4}$ Li I. Zhang, ${ }^{1,3}$ and Huizhong W. Tao ${ }^{1,2}$ \\ ${ }^{1}$ Zilkha Neurogenetic Institute, ${ }^{2}$ Department of Cell and Neurobiology, ${ }^{3}$ Department of Physiology and Biophysics, and ${ }^{4}$ Graduate Programs, Keck School of \\ Medicine, University of Southern California, Los Angeles, California 90089
}

Orientation selectivity (OS) of visual cortical neurons is progressively sharpened during development. However, synaptic circuit mechanisms underlying the OS sharpening remain unclear. In the current study, in vivo whole-cell voltage-clamp recordings from layer 4 excitatory neurons in the developing mouse primary visual cortex revealed changes of orientation tuning profiles of their excitatory and inhibitory inputs during a post-eye-opening period when OS of their spiking responses becomes sharpened. In addition to a parallel strengthening of excitation and inhibition during this developmental period, the orientation tuning of excitatory inputs keeps relatively constant, whereas the tuning of inhibitory inputs is broadened, and becomes significantly broader than that of excitatory inputs. Neuron modeling and dynamic-clamp recording demonstrated that this developmental broadening of the inhibitory tuning is sufficient for sharpening OS. Depriving visual experience by dark rearing impedes the normal developmental strengthening of excitation, but a similar broadening of inhibitory tuning, likely caused by a nonselective strengthening of inhibitory connections, results in the apparently normal OS sharpening in excitatory neurons. Our results thus provide the first demonstration that an inhibitory synaptic mechanism can primarily mediate the functional refinement of cortical neurons.

\section{Introduction}

The development of orientation selectivity (OS), a fundamental functional property of visual cortical neurons (Hubel and Wiesel, 1962; Ferster and Miller, 2000), has been extensively characterized in previous studies, especially at the level of extracellular spike signals. In many species other than primates (Wiesel and Hubel, 1974), OS matures over an extended period of postnatal life. In the cat, maturation of orientation tuning occurs in the first few weeks after birth (Hubel and Wiesel, 1963; Barlow and Pettigrew, 1971; Blakemore and Van Sluyters, 1975; Buisseret and Imbert, 1976; Frégnac and Imbert, 1978; Tsumoto and Suda, 1982; Albus and Wolf, 1984). In the ferret and rodent, it has been shown that OS progressively matures within weeks after the time of natural eye opening, with the percentage of orientationselective neurons gradually increased and the sharpness of orientation tuning enhanced (Chapman and Stryker, 1993; Fagiolini et al., 1994; Kuhlman et al., 2011; Rochefort et al., 2011). In parallel with the maturation of single-cell OS, orientation maps in the ferret, as detected by intrinsic optical imaging, also strengthen and become high contrast (Chapman et al., 1996; Gödecke et al., 1997; White et al., 2001).

\footnotetext{
Received Nov. 1, 2011; revised Jan. 16, 2012; accepted Feb. 2, 2012.

Author contributions: H.W.T. designed research; Y.-t.L., W.-p.M., and C.-j.P. performed research; Y.-t.L., C.-j.P., L.I.Z. and H.W.T. analyzed data; L.I.Z. and H.W.T. wrote the paper.

This work was supported by the National Institutes of Health Grant EY019049 and the Kirchgessner Foundation to H.W.T. L.I.Z. was supported by Grant DC008983.

Correspondence should be addressed to Huizhong W. Tao, Zilkha Neurogenetic Institute, Department of Cell and Neurobiology, University of Southern California, 1501 San Pablo Street, Los Angeles, CA 90089. E-mail: htao@usc.edu.

DOI:10.1523/JNEUROSCI.5514-11.2012

Copyright $\odot 2012$ the authors $\quad 0270-6474 / 12 / 323981-11 \$ 15.00 / 0$
}

Previous extracellular recording and imaging studies on the development of OS only examined spike outputs or outputrelated signals. The cellular and synaptic mechanisms underlying the developmental sharpening of OS remain uncertain. Theoretical work with activity-instructed, correlation-based models has shown that OS can arise from synaptic strengthening and elimination of excitatory neuronal connections, in particular, geniculocortical connections (Miller, 1992, 1994; Miyashita and Tanaka, 1992). Orientation-tuned cortical inhibitory neurons would also appear with these changes in excitatory connectivity (Kayser and Miller, 2002). These results have suggested that a refinement of excitatory circuits is a major driving force for the sharpening of OS. However, it is possible that changes in both excitatory and inhibitory inputs can contribute significantly to the development of OS, based on the results of many studies of adult sensory cortices, which have shown that the excitatory input usually determines the tuning preference, while inhibition sharpens the tuning selectivity of output responses (Ben-Yishai et al., 1995; Somers et al., 1995; Troyer et al., 1998; Wehr and Zador, 2003; Zhang et al., 2003; Tan et al., 2004; Mariño et al., 2005; Wu et al., 2008; Liu et al., 2011). During development, both the amplitude and the tuning profile of excitatory and inhibitory synaptic inputs may undergo drastic changes. If we ignore detailed changes in synaptic strength, in principle two prominent mechanisms can account for the OS sharpening (see Fig. $1 A$ ). First, the tuning profile of excitatory inputs is sharpened during development. Second, the tuning profile of inhibitory inputs is broadened, which can also effectively enhance tuning selectivity (Somers et al., 1995; Lauritzen and Miller, 2003; Ringach et al., 2003; Wu et al., 2008; Liu et al., 2011). In this study, we have performed in vivo whole-cell voltage-clamp recordings from 
layer 4 excitatory neurons in the mouse primary visual cortex (V1) to distinguish these potential synaptic mechanisms.

\section{Materials and Methods}

Animal preparation. All experimental procedures used in this study were approved by the Animal Care and Use Committee of the University of Southern California. Female C57BL/6 mice from P14 to P90 were used. Animal were sedated with an intraperitoneal injection of chlorprothixene $(5 \mathrm{mg} / \mathrm{kg})$ and then anesthetized with urethane $(0.5 \mathrm{~g} / \mathrm{kg}$, i.p., at $10 \%$ $\mathrm{w} / \mathrm{v}$ in saline), as previously described (Niell and Stryker, 2008; Liu et al., $2009,2010)$. The animal's body temperature was maintained at $\sim 37.5^{\circ}$ by a heating pad (Harvard Apparatus). A tracheotomy was performed, and a small glass capillary tube was inserted to maintain a free airway. CSF draining was performed. The part of the skull and dura mater $(\sim 1 \times$ $1 \mathrm{~mm}$ ) over the V1 was removed. Artificial CSF (ACSF) solution [containing as follows (in mM): $140 \mathrm{NaCl}, 2.5 \mathrm{KCl}, 2.5 \mathrm{CaCl}_{2}, 1.3 \mathrm{MgSO}_{4}, 1.0$ $\mathrm{NaH}_{2} \mathrm{PO}_{4}, 20$ HEPES, 11 glucose, $\mathrm{pH}$ 7.4] was applied to the exposed cortical surface when necessary. The eyes were covered with ophthalmic lubricant ointment until recording, at which time the eyes were rinsed with saline and a thin layer of silicone oil (30,000 centistokes) was applied to prevent drying while allowing clear optical transmission. The eye movement and receptive field drift of single units were negligible within the recording time windows (Mangini and Pearlman, 1980; Liu et al., 2010).

In vivo electrophysiology. Whole-cell voltage-clamp recordings were performed with an Axopatch 200B (Molecular Devices) according to previous studies (Liu et al., 2010). The patch pipette had a tip opening of $\sim 2 \mu \mathrm{m}\left(4.5-6 \mathrm{M} \Omega\right.$ ). For most whole-cell recordings, we used a $\mathrm{Cs}^{+}$. based intrapipette solution containing the following (in $\mathrm{mM}$ ): $125 \mathrm{Cs}-$ gluconate, 5 TEA-Cl, 4 MgATP, 0.3 GTP, 8 phosphocreatine, 10 HEPES, 10 EGTA, 2 CsCl, 1 QX-314, 0.75 MK-801, pH 7.25. A K ${ }^{+}$-based intrapipette solution [containing the following (in $\mathrm{mM}$ ): $130 \mathrm{~K}$-gluconate, 2 $\mathrm{KCl}, 1 \mathrm{CaCl}_{2}$, $4 \mathrm{MgATP}, 0.3 \mathrm{GTP}, 8$ phosphocreatine, 10 HEPES, 11 EGTA, pH 7.25] was used in some current-clamp recordings to measure resting membrane potential and spike threshold. The pipette and wholecell capacitance were compensated completely, and series resistance (25-50 M $\Omega$ ) was compensated by $50-60 \%$ (100 $\mu \mathrm{s} \mathrm{lag})$. An $11 \mathrm{mV}$ junction potential was corrected. Signals were filtered at $2 \mathrm{kHz}$ for voltage-clamp recording and $5 \mathrm{kHz}$ for current-clamp recording and sampled at $10 \mathrm{kHz}$. The evoked excitatory and inhibitory currents were resolved by clamping cells at -70 and $0 \mathrm{mV}$, respectively. As discussed before, our whole-cell recording method highly biases sampling toward pyramidal neurons (Liu et al., 2009, 2010). For loose-patch cell-attached recordings, glass electrodes containing the $\mathrm{K}^{+}$-based solution or ACSF were used. A 100-250 M $\Omega$ seal was formed on the targeted neuron. The pipette capacitance was completely compensated. Spikes were recorded in voltage-clamp mode, with a commend potential applied to achieve a zero baseline current. The spike signal was filtered at $10 \mathrm{kHz}$ and sampled at $20 \mathrm{kHz}$. For recording of fast-spiking (FS) inhibitory neurons, we used pipettes with smaller openings (10 M $\Omega$ ). FS neurons were actively searched and identified by narrow spike waveforms (through-to-peak intervals $<0.5 \mathrm{~ms}$ ) (Liu et al., 2009). All neurons recorded in this study were located at a depth of 375-500 $\mu \mathrm{m}$ below the pia according to the microdrive reading, corresponding to layer 4 . According to previous results, the majority of layer 4 excitatory cells are simple cells based on response modulation (Niell and Stryker, 2008) and spiking receptive field structure (Liu et al., 2009, noted that monocontrast cells with one subfield can be considered as simple).

Visual stimulation. Software for data acquisition and visual stimulation was custom developed with LabVIEW (National Instruments) and MATLAB (Mathworks), respectively. Visual stimuli were provided by a $34.5 \times 25.9 \mathrm{~cm}$ monitor (refresh rate $120 \mathrm{~Hz}$, mean luminance $\sim 12$ $\mathrm{cd} / \mathrm{m}^{2}$ ) placed $0.25 \mathrm{~m}$ away from the right eye. A distance of $0.25 \mathrm{~m}$ from the mouse eye is equivalent to infinity (Liu et al., 2010). The center of monitor was placed at $45^{\circ}$ azimuth and $0^{\circ}$ elevation, and it covered $\pm 35^{\circ}$ horizontally and $\pm 27^{\circ}$ vertically of the mouse visual field. Recordings were made mostly in the monocular zone of the V1. To measure orientation tuning, drifting sinusoidal gratings $\left(2 \mathrm{~Hz}, 0.04 \mathrm{cycle} /{ }^{\circ}\right.$, contrast 0.35 ) of 12 directions ( $30^{\circ}$ step) were applied. Stationary grating of one orientation was first presented on the full screen for $1.8 \mathrm{~s}$ before it drifted for $1.5 \mathrm{~s}$. The grating stopped drifting for $500 \mathrm{~ms}$ before another grating pattern appeared. The 12 patterns were presented in a random sequence, and were repeated 5-10 times. Spontaneous activity was recorded when a uniform gray background was applied.

Data analysis. Spikes were sorted off-line. Spikes evoked by drifting gratings were counted within a $70-1570 \mathrm{~ms}$ window after the start of drifting. The spontaneous firing rate was subtracted from the stimulusevoked spike rate. Responses with peak firing rates exceeding spontaneous firing rate plus 3 SDs were considered significant. The strength of orientation selectivity was quantified with a global OS index (OSI; i.e., 1 - circular variance) (Ringach et al., 2002):

\section{Global OSI}

$$
=\sqrt{\left(\sum_{i}\left(R\left(\theta_{i}\right) * \sin \left(2 \theta_{i}\right)\right)\right)^{2}+\left(\sum_{i}\left(R\left(\theta_{i}\right) * \cos \left(2 \theta_{i}\right)\right)\right)^{2}} / \sum_{i} R\left(\theta_{i}\right),
$$

where $\theta_{i}$ is the angle of the moving direction of the grating, and $R\left(\theta_{i}\right)$ is the response level at angle $\theta_{i}$. For measuring the tuning width, the response levels for drifting sinusoidal gratings of two directions at the same orientation were averaged to obtain the orientation tuning curve between $0^{\circ}$ and $180^{\circ}$, which was then fit with a Gaussian function $R(\theta)=$ $A^{*} \exp \left(-0.5^{\star}[\theta-\varphi]^{2} / \sigma^{2}\right)+B . \varphi$ is the preferred orientation. Tuning width was the half-width at half-maximum of the fit above the baseline $B$. The standard OSI was quantified as $\left(R_{\text {pref }}-R_{\text {orth }}\right) /\left(R_{\text {pref }}+R_{\text {orth }}\right)=$ $A /\left(A+2{ }^{\star} B\right)$, where $R_{\text {pref }}$ is the response level at the angle of $\varphi$, and $R_{\text {orth }}$ is that at the angle of $\varphi+90^{\circ}$.

The recorded synaptic responses were cycle averaged, and then were smoothed by averaging within a $40 \mathrm{~ms}$ sliding window. Excitatory and inhibitory synaptic conductances were derived based on the following equation (Wehr and Zador, 2003; Liu et al., 2010):

$$
I(t)=G_{r}\left[V(t)-E_{r}\right]+G_{e}(t)\left[V(t)-E_{e}\right]+G_{i}(t)\left[V(t)-E_{i}\right],
$$

where $I(t)$ is the amplitude of current at any time point; $G_{r}$ and $E_{r}$ are the resting leak conductance and resting membrane potential, respectively, and were determined from the baseline recordings in each experiment; $G_{e}$ and $G_{i}$ are the excitatory and inhibitory synaptic conductance, respectively; $V(t)$ is the membrane voltage; and $E_{e}(0 \mathrm{mV})$ and $E_{i}(-70 \mathrm{mV})$ are the reversal potentials. $V(t)$ is corrected by $V(t)=V_{h}-R_{s}{ }^{*} I(t)$, where $R_{s}$ is the effective series resistance and $V_{h}$ is the applied holding voltage. The peak conductance as well as the integral was quantified. Orientation tuning of synaptic conductance was analyzed in a similar way, as described above.

Modeling. A conductance-based integrate-and-fire neuron model (Troyer et al., 1998; Wehr and Zador, 2003; Liu et al., 2010) was used to simulate the membrane potential response, as follows:

$$
\begin{array}{r}
V_{m}(t+d t)=-\frac{d t}{C}\left[G_{e}(t) *\left(V_{m}(t)-E_{e}\right)+G_{i}(t) *\left(V_{m}(t)-E_{i}\right)\right. \\
\left.+G_{r}\left(V_{m}(t)-E_{r}\right)\right]+V_{m}(t),
\end{array}
$$

where $V_{m}(t)$ is the membrane potential at time $t, C$ the whole-cell capacitance, $G_{r}$ is the resting leak conductance, and $E_{r}$ is the resting membrane potential $(-65 \mathrm{mV}) . E_{e}$ and $E_{i}$ were set at 0 and $-75 \mathrm{~m} \mathrm{~V}$, respectively. $C$ was set as $50 \mathrm{pF}$, which was the averaged capacitance value in our wholecell recordings. $G_{r}$ was calculated based on the equation $G_{r}=C^{\star} G_{m} / C_{m}$, where $G_{m}$, the specific membrane conductance, is $1 \mathrm{e}-5 \mathrm{~S} / \mathrm{cm}^{2}$, and $C_{m}$, the specific membrane capacitance, is $1 \mathrm{e}-6 \mathrm{~F} / \mathrm{cm}^{2}$.

Synaptic conductance evoked by a moving grating was simulated by fitting the average waveform of synaptic response with a skew normal distribution function (Azzalini, 1985), which yielded a better fit than sinusoidal functions or $\alpha$ functions, as follows:

$$
f(x)=\text { amplitude } \times \frac{2}{\omega} \phi\left(\frac{x-\xi}{\omega}\right) \times \Phi\left(\alpha\left(\frac{x-\xi}{\omega}\right)\right)+\text { baseline }
$$

where $\phi$ and $\Phi$ are the standard normal probability density function and the cumulative distribution function, respectively, and $\xi$ determines the 
location. The scale factor $(\omega)$ was set at $145 \mathrm{~ms}$, and the shape factor $(\alpha)$ at 1.5 for both excitatory and inhibitory conductances. The synaptic conductance was set as 0 if it was $<10 \%$ of maximum, so we could exclude a very slow rising phase. We quantified the phase difference between excitation and inhibition for optimally evoked responses. It was $17 \pm 14^{\circ}$ at stage $1(\mathrm{ST} 1 ; \sim \mathrm{P} 15-\mathrm{P} 19 ; n=13), 22 \pm 15^{\circ}$ at ST2 (P21-P30; $n=14)$, and there was no significant difference between ST1 and ST2 ( $p>0.1, t$ test). Based on these experimental observations, inhibition was set with a $25 \mathrm{~ms}$ delay relative to that of excitation (corresponding to an $18^{\circ}$ phase difference). Varying the relative delay of inhibition from 5 to $50 \mathrm{~ms}$ did not affect our conclusion (data not shown). To simulate responses to different orientations, the shape of evoked synaptic conductance did not change but the peak amplitude did vary according to the tuning curves created based on the average OSI in our experimental data (see Fig. $3 B$ ). The peak amplitudes of $G_{e}$ and $G_{i}$ in the first cycle were based on average experimental data ( $1.63 \mathrm{nS}$ for excitation and $2.78 \mathrm{nS}$ for inhibition at ST1; 2.76 and $5.62 \mathrm{nS}$, respectively, at ST2). The peak amplitudes in the second and the third cycles were determined by the adaptation factor assigned.

Dynamic clamp. Dynamic-clamp recordings were performed as described by Nagtegaal and Borst (2010). The current injected into the cell was calculated in real time by a custom-written LabVIEW routine and controlled by National Instruments interface, as follows:

$$
I(t)=G_{e}(t) *\left(V_{m}(t)-E_{e}\right)+G_{i}(t) *\left(V_{m}(t)-E_{i}\right) .
$$

The time-dependent $G_{\mathrm{e}}$ and $G_{\mathrm{i}}$ were similar to those shown in Figure $3 A$. $E_{\mathrm{e}}$ and $E_{\mathrm{i}}$ were set as 0 and $-70 \mathrm{mV}$, respectively. The $V_{\mathrm{m}}$ was sampled at $5 \mathrm{kHz}$. The junction potential was corrected. Measurements of $V_{\mathrm{m}}$ were corrected off-line for the voltage drop on the uncompensated residual series resistance $(15-20 \mathrm{M} \Omega)$. The corrected $V_{\mathrm{m}}$ differed only slightly from the recorded $V_{\mathrm{m}}$.

\section{Results \\ Development of OS in layer 4 excitatory neurons of mouse visual cortex}

To understand the progression of the developmental sharpening of OS in the mouse visual cortex, we performed in vivo, blind, single-cell loose-patch recordings in layer 4 (see Materials and Methods). Our recording method resulted in highly biased samplings from excitatory neurons (Liu et al., 2009, 2010; Ma et al., 2010), as evidenced by the broad spike waveforms observed in all the recorded cells. The cells were pooled into three age groups: within $5 \mathrm{~d}$ after the time of eye opening (ST1, P15-P19), during the critical period for ocular dominance plasticity (ST2, P21P30), and in adulthood (P70-P100). As shown by the poststimulus spike-time histograms for the responses of example cells to drifting sinusoidal gratings (Fig. $1 B$ ), orientation tuning of spiking responses was usually broad at ST1, while sharp tuning appeared in a significant number of cells at ST2. To quantify the degree of OS, we used a global OSI, which is a good single metric for OS that takes into account responses to all orientations (Ringach et al., 2002). The cumulative distribution of global OSIs shifted rightward from ST1 to ST2, indicating that OS is developmentally sharpened (Fig. 1C). The mean global OSI ( $\pm \mathrm{SD}$ ) was $0.27 \pm 0.21$ at ST1, $0.44 \pm 0.22$ at ST2, and $0.42 \pm 0.22$ in adulthood. The distribution of global OSIs did not differ between ST2 and adulthood (Fig. 1C), indicating that the maturation of OS in the mouse largely occurs during ST1. Indeed, when we further divided ST1 into two substages, within $2 \mathrm{~d}$ of eye opening and 3-5 d after eye opening, we found that there was a marked difference in global OSI between the substages (from $0.22 \pm 0.17$ to $0.35 \pm 0.23$, mean $\pm \mathrm{SD}, n=11$ and 14 , respectively; $p<0.05$, $t$ test). This indication of a fast maturation of OS within days of eye opening is consistent with results reported previously (Wang et al., 2010). Matching with the measurement of global OSI, the tuning width (see Materials and Methods) was reduced from ST1 to ST2 (from $39.2 \pm 17.4^{\circ}$ to $27.2 \pm 17.8^{\circ}$, mean $\pm \mathrm{SD} ; p<0.01$, $t$ test). The sharpening of orientation tuning can be attributed to both an increase in spike rate in response to optimal orientation and, importantly, a decrease in spike rate to orthogonal orientation (Fig. $1 D$ ). Together with the fact that the average spontaneous firing rate was reduced during the same period (Fig. $1 D$ ), it appears that there is a general increase in inhibitory tone in the cortex during development (Morales et al., 2002; Chattopadhyaya et al., 2004). Based on the developmental progression of spiking response selectivity, we chose to compare excitatory and inhibitory synaptic tuning profiles between ST1 and ST2.

\section{Synaptic inputs underlying OS during development}

To dissect visually evoked excitatory and inhibitory inputs, we performed in vivo whole-cell voltage-clamp recordings (see Materials and Methods). We recorded synaptic responses to drifting gratings when clamping the cell's membrane potential at two levels, -70 and $0 \mathrm{mV}$ (Liu et al., 2010). In all cells, excitatory and inhibitory synaptic responses were observed at all testing orientations (Fig. $1 E$ ). In many cases, excitatory and inhibitory responses showed an evident adaptation, i.e., reducing response level with increasing stimulus cycles (Fig. $1 E$ ), although there were cases in which the maximum conductance occurred during the later cycles. Interestingly, adaptation was much less obvious in spiking responses (Fig. $1 \mathrm{~B}$ ). Two measurements were applied to quantify the level of synaptic responses. In the first, we followed convention and averaged the synaptic responses by cycles, and then measured the peak conductance after smoothing the response curve with a $40 \mathrm{~ms}$ sliding window for averaging. In the second, we measured the peak conductance in the first cycle of smoothed responses. Values of these two measures were used to plot the synaptic tuning curve. In the example the cell P17, excitation and inhibition appeared to have a similar preferred orientation, and the inhibitory tuning appeared slightly narrower than excitation (Fig. $1 E$ ). In comparison, in the example the cell P24, while the excitatory tuning was similar to that in the P17 cell, the inhibitory tuning appeared much broader and was broader than the excitatory tuning in both measures (Fig. $1 F$ ).

The trend of a broadening of inhibition was evident in responses of many other cells (Fig. 2A,B). Data were summarized for a total of 13 ST1 cells and 14 ST2 cells. Analysis of peak conductance of cycle-averaged waveforms showed that at ST1, the tuning selectivity of inhibition was slightly but significantly higher than that of excitation ( $p<0.01$, paired $t$ test) (Fig. $2 C$, left). From ST1 to ST2, there was no change in tuning selectivity of excitation ( $p=0.32, t$ test), while that of inhibition was greatly reduced ( $p<0.001, t$ test) and became significantly lower than that of excitation ( $p<0.001$, paired $t$ test) (Fig. $2 C$, left). Essentially the same conclusion could be made when the integral conductance was measured (data not shown), and when the peak conductance in the first cycle was measured, except that at ST1 inhibitory selectivity did not differ significantly from excitatory selectivity (Fig. 2C, right). Thus, the orientation tuning profile of excitatory inputs remained largely unchanged, while that of inhibitory inputs became less selective. The preferred orientation of inhibition was largely identical to that of excitation (Fig. $2 D$ ), and their difference $\left(\Delta \theta_{\text {pref }}\right)$ was on average $18.4 \pm 8.8^{\circ}$ (mean \pm SD) at ST1 and $20.5 \pm 7.9^{\circ}$ at ST2 $(p=0.64, t$ test $)$. To further reveal the developmental changes in synaptic tuning profiles, we averaged the normalized synaptic tuning curves of all cells, which were aligned according to the optimal orientation (Fig. $2 E$ ). The average inhibitory tuning curve was similar to or slightly nar- 
A

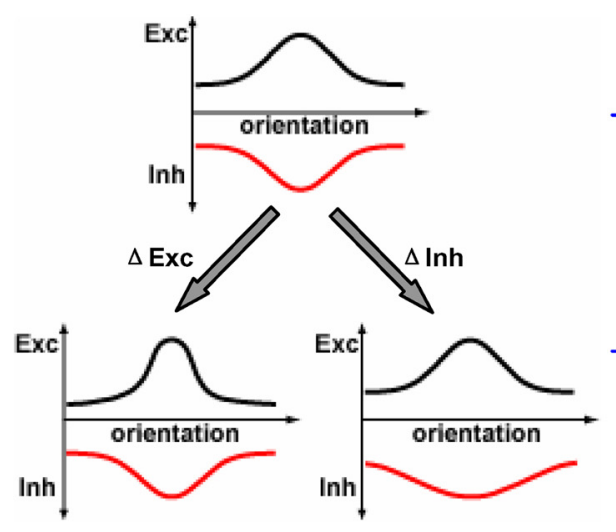

E
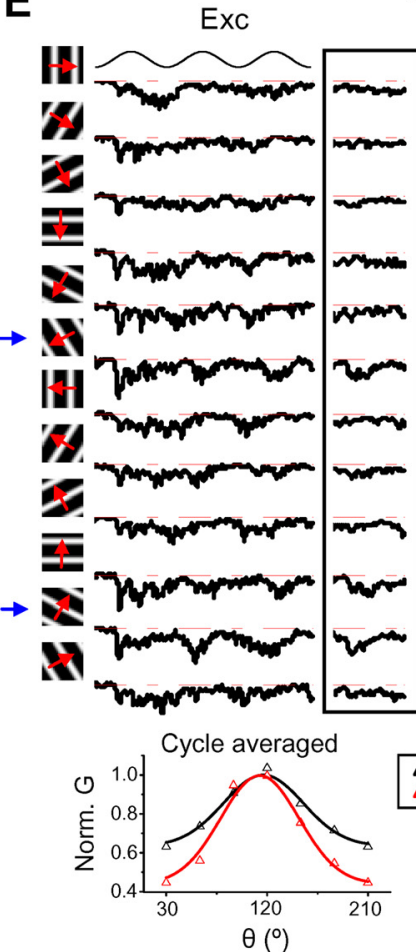

B

H.

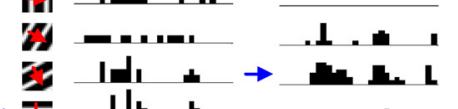

$\rightarrow$ ․․

:

$$
\text { . }
$$$$
\text { 闻 }
$$$$
\text { a d - }
$$

Jinit.

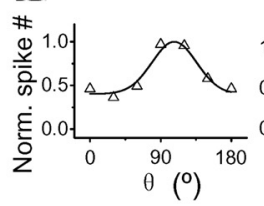

$\theta\left({ }^{\circ}\right)$

ST1

\section{$F$}

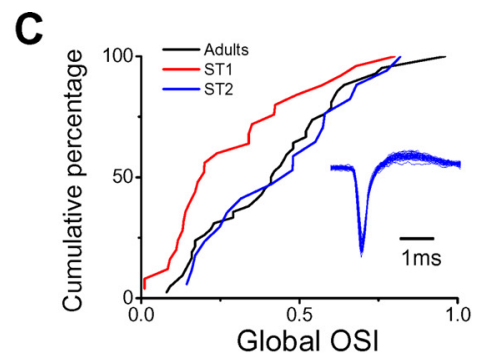

D

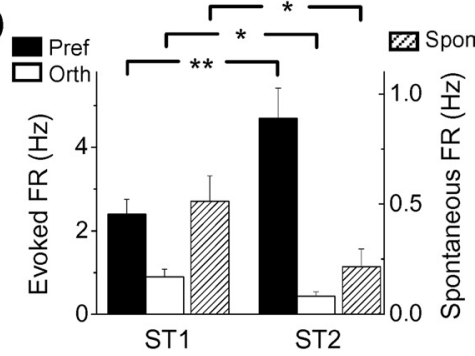

ST2

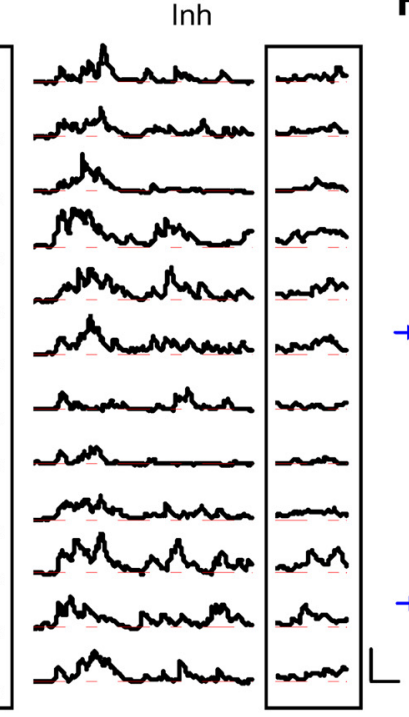

First cycle
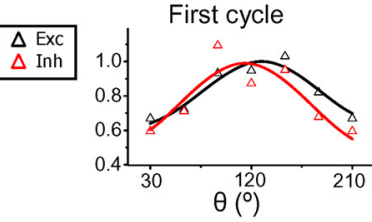

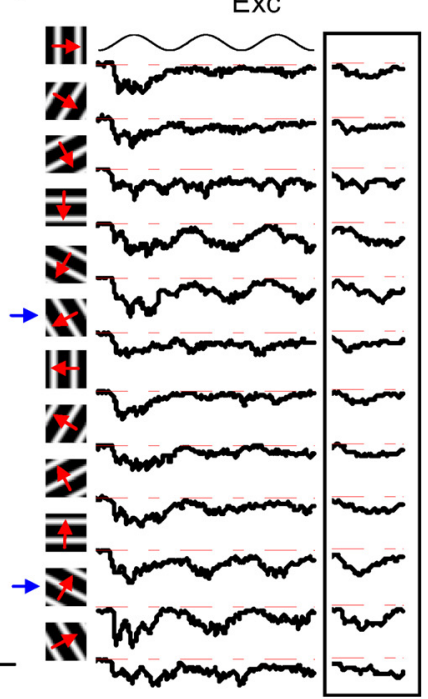

Cycle averaged

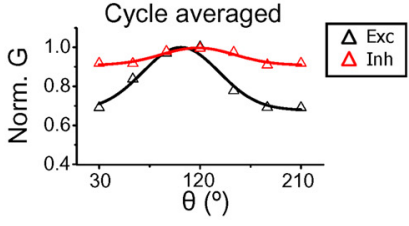

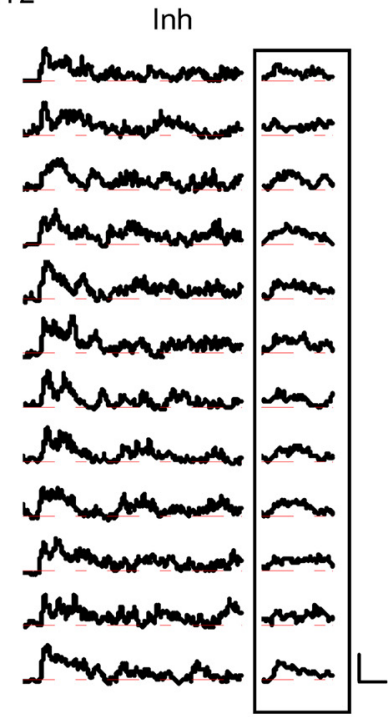

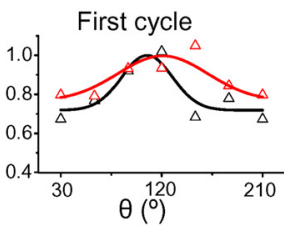

Figure 1. Developmental sharpening of OS in mouse visual cortex. $A$, Two potential synaptic models for the developmental sharpening of OS. Black and red curves represent the orientation tuning curve of excitatory (Exc) and inhibitory (Inh) inputs, respectively. Increasing tuning selectivity of excitation (bottom left) or decreasing tuning selectivity of inhibition (bottom right) can both lead to a sharpening of selectivity of output responses. $\boldsymbol{B}$, Two example layer 4 excitatory neurons at stages indicated. Plots are poststimulus spike time histograms for their responses to drifting sinusoidal gratings at various directions (indicated on the left). Bottom, The normalized orientation tuning curve of the spike count and the corresponding Gaussian fit. Calibration: $12 \mathrm{~Hz}$ (left) and $18 \mathrm{~Hz}$ (right) and $150 \mathrm{~ms}$. Blue arrows point to the optimal orientation. C, Cumulative distribution of global OSI for layer 4 excitatory neurons in different age groups. ST1, $n=25 ;$ ST2, $n=17$; adult, $n=42$. Inset, Superimposed individual spike waveforms for an example excitatory neuron. Note that the trough-to-peak interval is longer than $0.5 \mathrm{~ms}$. ST1 differs significantly from ST2 and adult ( $p<0.05$, Mann-Whitney test). ST2 does not differ from adult ( $p=0.56$, Mann-Whitney test). $D$, Average evoked firing rate (FR) for preferred (dark) and orthogonal (white) orientations, as well as the average spontaneous firing rate (hatch) of excitatory neurons at ST1 $(n=25)$ and ST2 $(n=17)$. Error bars indicate SEM. ${ }^{*} p<0.05 ;{ }^{* *} p<0.01 ; t$ test. E, Average excitatory and inhibitory synaptic currents evoked by drifting gratings at various directions for an example layer 4 excitatory neuron (at P17). Stimulus cycles are labeled on top. Boxed are cycle-averaged response waveforms. Calibration: 100 (Exc)/140 (Inh) pA, 200 ms. Bottom, Normalized orientation tuning curves of peak excitatory (black) and inhibitory (red) conductances of the cycle-averaged waveform (left) or of the first cycle (right) and the corresponding Gaussian fits. $\boldsymbol{F}$, A sample cell at P24. Data presentation is the same as in $\boldsymbol{E}$. Calibration: 200 (Exc)/275 (Inh) pA, $200 \mathrm{~ms}$.

rower than the average excitatory tuning curve at ST1, but became significantly broader than the excitatory tuning at ST2 (Fig. $2 E)$. The average tuning width of excitation was $36.3 \pm 15.1^{\circ}$ at $\mathrm{ST} 1$ and $35.7 \pm 11.3^{\circ}$ at ST2 (mean $\pm \mathrm{SD} ; p>0.4, t$ test), while that of inhibition was $31.4 \pm 7.5^{\circ}$ at ST1 and $44.2 \pm 16.6^{\circ}$ at ST2 $(p<0.02, t$ test $)$ when the peak conductance of cycle-averaged responses was measured. Similarly, tuning width of excitation was $37.8 \pm 15.3^{\circ}$ at ST1 and $34.9 \pm 11.1^{\circ}$ at ST2 $(p>0.1)$, and that of inhibition was $36.6 \pm 16.1^{\circ}$ at ST1 and $47.6 \pm 18.6^{\circ}$ at ST2 $(p<0.02)$ when considering the peak conductance of the first cycle. The data indicate that the developmentally reduced selectivity of inhibitory tuning cannot be merely attributed to a gen- 
A

ST1

Cell \#2 Cell \#3 Cell \#4 Cell \#5

B

ST2
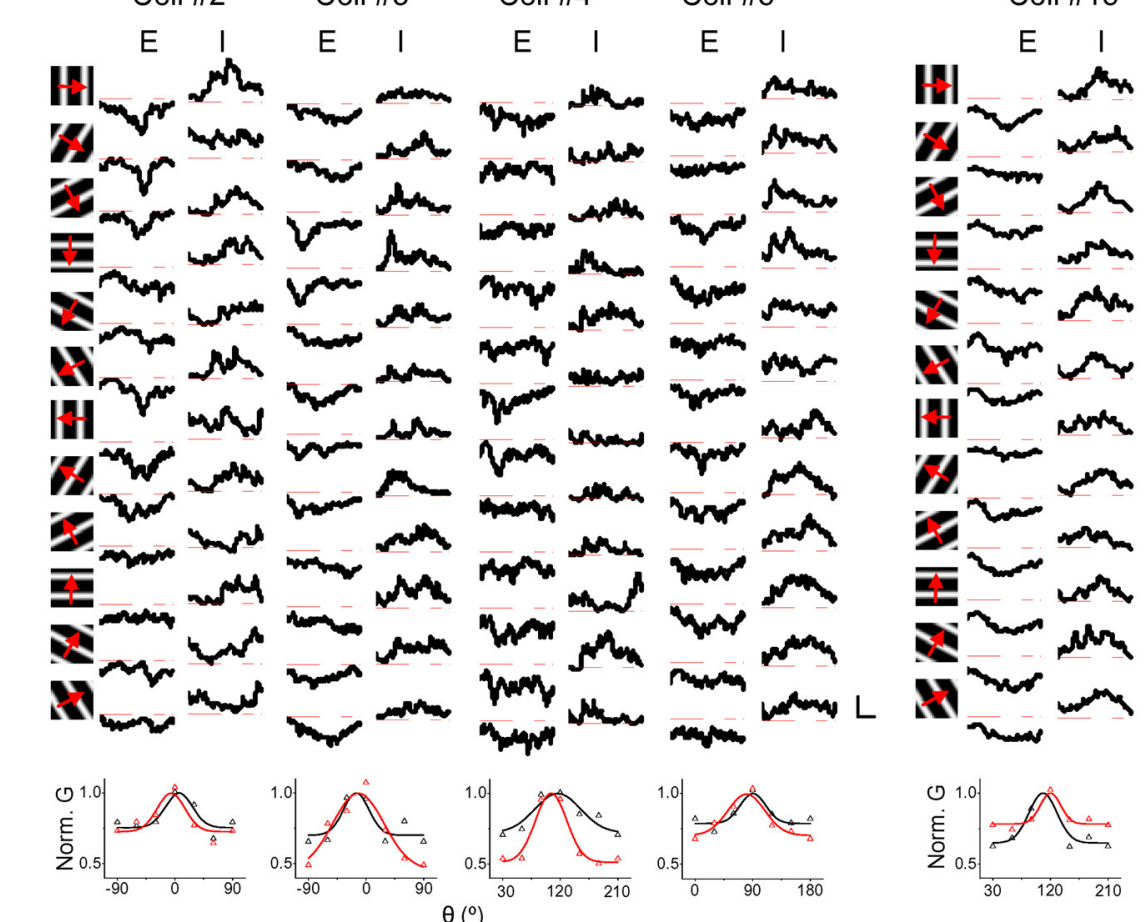

Cell \#16

Cell \#17

Cell \#18

C
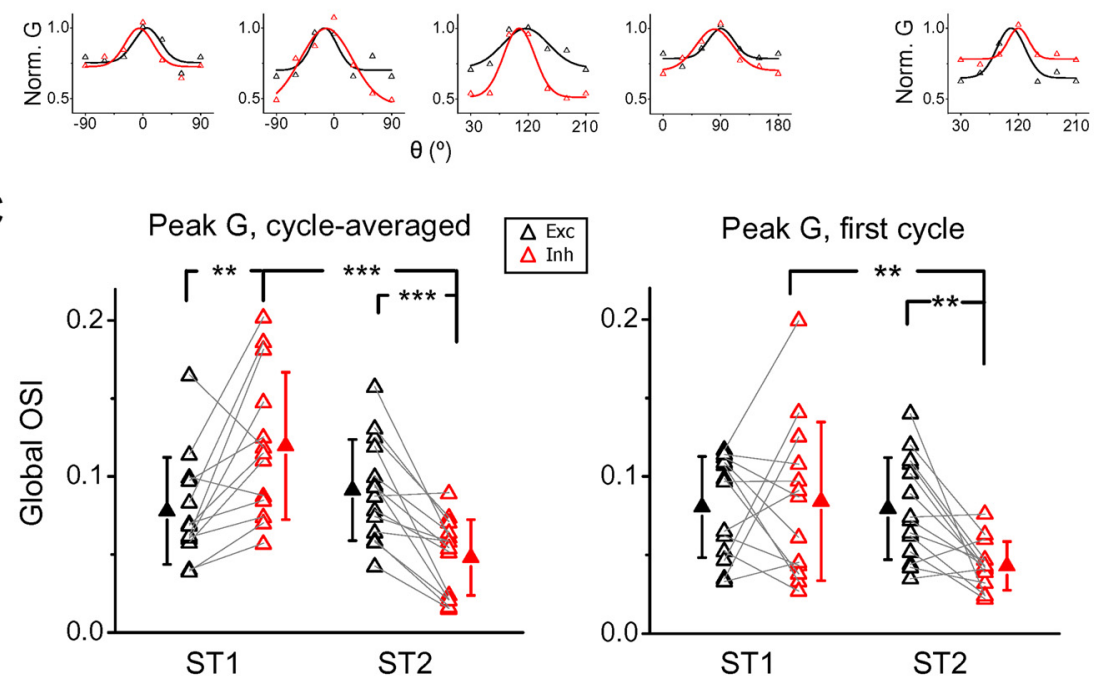

E

$\sin$

E I

E I
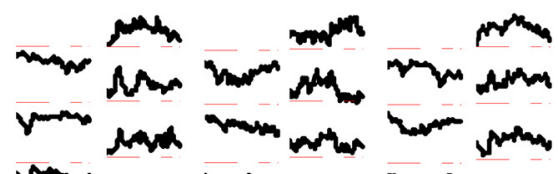

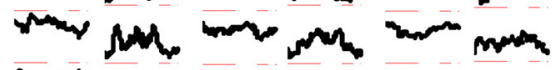

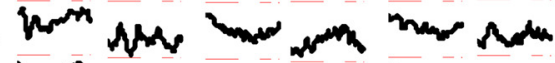

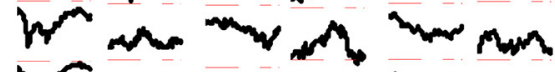

Wr arom

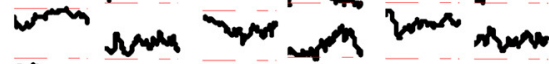

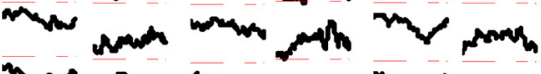

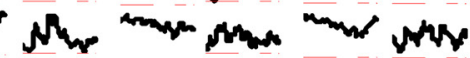

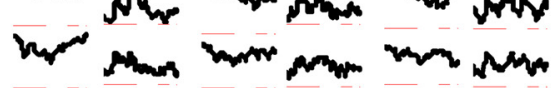

mor mis
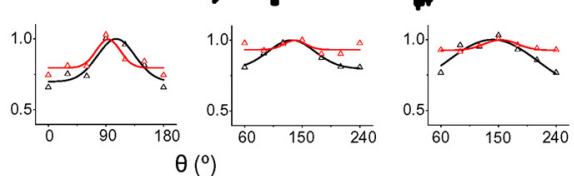

D

$\mathbf{E}$

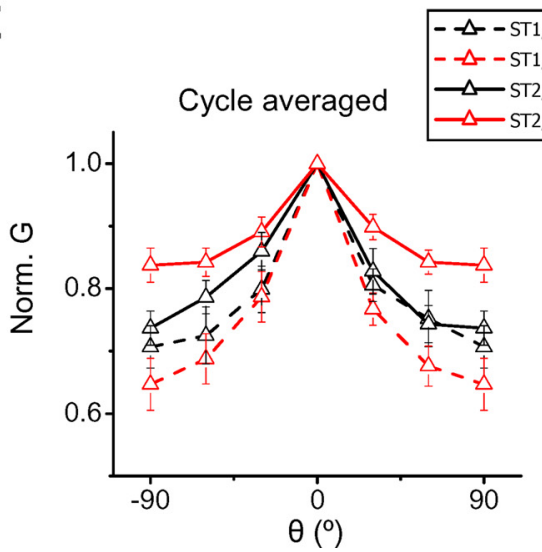

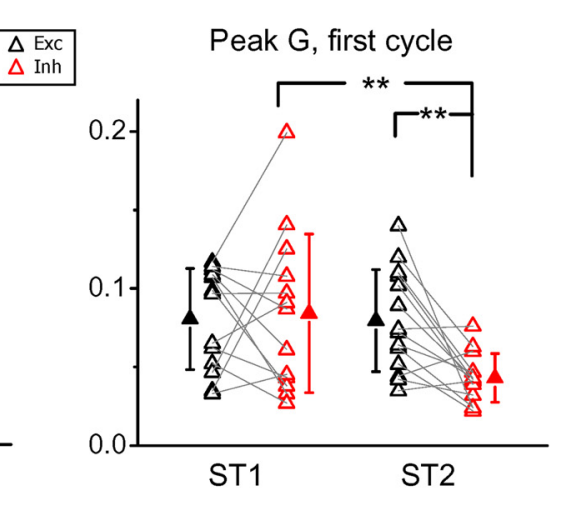

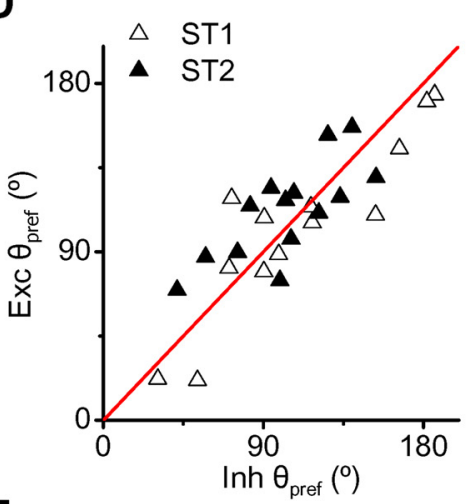

$\mathbf{F}$

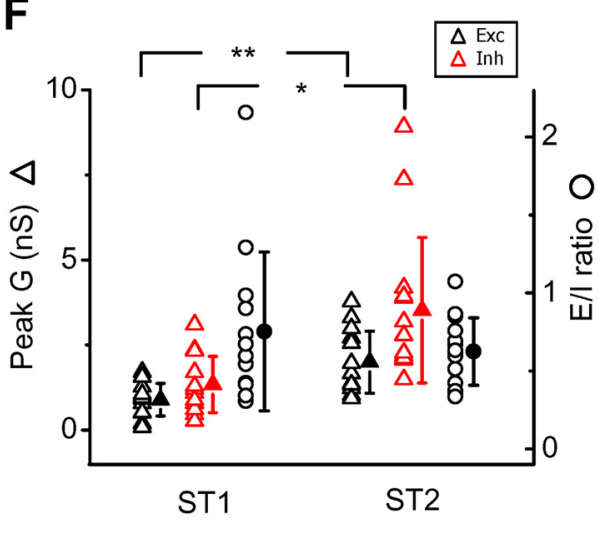

Figure 2. Synaptic inputs underlying $0 S$ of developing layer 4 excitatory neurons. A, Cycle-averaged excitatory (Exc/E) and inhibitory (Inh/I) responses for more layer 4 excitatory neurons at ST1. Calibration: Cell 2, 32.6 (E)/50.2 (I) pA; Cell 3, 27.2 (E)/48.8 (I) pA; Cell 4,32.2 (E)/44.5 (I) pA; Cell 5, 51.6 (E)/71.6 (I) pA, and 100 ms. Bottom, Synaptic tuning curves. Black, Excitation; red, inhibition. B, More example layer 4 excitatory neurons at ST2. Calibration: Cell 15, 54.4 (E)/62.2 (I) pA; Cell 16, 74.6 (E)/89.4 (I) pA; Cell 17, 49.7 (E)/62.3 (I) pA; Cell 18, 43.8 (E)/63.6 (I) pA, and 100 ms. C, Distribution of global OSIs for excitation (black) and inhibition (red) at ST1 $(n=13)$ and ST2 $(n=14)$. Left, Based on measurements of peak conductance of the cycle-averaged response. Right, Based on peak conductance in the first cycle. Solid symbols represent mean \pm SD. Data points from the same cell are connected with a line. ${ }^{*} p<0.05 ;{ }^{* *} p<0.01 ;{ }^{* * *} p<0.001$; paired $t$ test or $t$ test. There is no significant difference in excitatory tuning selectivity between ST1 and ST2 $(p>0.1)$. D. Plot of preferred orientation angle of excitation versus that of inhibition. Red line is the identity line. There is no significant difference in preferred angle between excitation and inhibition at ST1 and ST2 ( $p>0.1, t$ test), based on measurements of peak conductance of the cycle-averaged response or that of the first cycle (data not shown). $\boldsymbol{E}$, Average excitatory and inhibitory tuning profiles. Synaptic tuning curves for individual cells were normalized and (Figure legend continues.) 
eral increase of untuned inhibitory activity, but there is a broadening of input. Finally, we observed that the strengths of both excitation and inhibition evoked by the optimal orientation were increased from ST1 to ST2 (Fig. 2F). This developmental increase in excitatory and inhibitory synaptic strength is consistent with previous in vitro results in visual cortical slices (Blue and Parnavelas, 1983; Morales et al., 2002; Chattopadhyaya et al., 2004). The fold increase was similar for excitation and inhibition, so that the overall excitation/inhibition ratio did not change significantly (Fig. $2 F$ ).

\section{An inhibitory mechanism for the developmental sharpening of OS}

The results above indicate two concurrent processes associated with the development of OS. First, there was a scaling up of the excitatory tuning curve by strengthening excitatory responses to different orientations multiplicatively, as reflected by the unchanged excitatory tuning profile (Fig. 2E, black). Second, although inhibitory inputs were also strengthened, the response to the orthogonal orientation was strengthened relatively more than that of the preferred orientation, resulting in a broadening of the inhibitory tuning profile (Fig. $2 E$, red). To understand how the synaptic strengthening per se and the developmental broadening of inhibitory tuning might contribute to the sharpening of OS, we performed simulations of neuronal responses by using a simple conductance-based integrate-and-fire neuron model (Liu et al., 2011), using parameter values (e.g., synaptic strength and synaptic tuning profile) observed in our experiments. We simulated synaptic conductance waveforms with a skew normal function (Fig. $3 A$, top), with the inhibitory response delayed relative to the excitatory response by $25 \mathrm{~ms}$ (see Materials and Methods). For simulating synaptic responses evoked by stimuli of multiple cycles, we quantified an adaptation factor (i.e., the ratio of the peak response amplitude in a cycle to that in the previous) for optimally evoked excitation and inhibition at two stages. For excitation, it was $0.65 \pm 0.17$ at ST1 and $0.69 \pm 0.19$ at ST2 (mean \pm SD). For inhibition, it was $0.53 \pm 0.21$ at ST1 and $0.6 \pm$ 0.21 at ST2. Consistent with a previous study (Tan et al., 2011), adaptation of inhibition was slightly stronger than that of excitation ( $p<0.05$ at ST1 and ST2, paired $t$ test). Because there was no significant difference in adaptation between ST1 and ST2 $(p>$ 0.1 for excitation and inhibition, $t$ test), we assigned an average adaptation factor of 0.67 to excitation and 0.57 to inhibition. As shown in Figure $3 A$ (bottom), although synaptic responses adapted substantially, the resulting $V_{\mathrm{m}}$ responses showed almost no adaptation. This modeling result provides an explanation for the less obvious adaptation in spiking responses than synaptic responses. The synaptic tuning profiles in the modeling were based on the average tuning curves in our experimental data. Although the excitatory tuning changed little from ST1 to ST2, the inhibitory tuning was broadened (Fig. $3 B$ ). We applied dif-

(Figure legend continued.) aligned according to the optimal orientation (set as $0^{\circ}$ ) before averaging. Error bars indicate SEM. Excitatory and inhibitory tuning curves were aligned independently. Because excitation and inhibition shared a similar preferred orientation, the plotted average excitatory and inhibitory tuning curves were given the same optimal orientation. Left, Based on peak conductance of the cycle-averaged response. Right, Based on peak conductance in the first cycle. $\boldsymbol{F}$, Peak excitatory (black) and inhibitory (red) conductances of cycle-averaged responses to optimally oriented gratings (triangle), and their ratio (E/I ratio, circle). Solid symbols represent mean $\pm S D .{ }^{*} p<0.05 ;{ }^{* *} p<0.01 ; t$ test. The $\mathrm{E} / \mathrm{I}$ ratio was $0.65 \pm 0.27$ at ST1 and $0.53 \pm 0.21$ at ST2 $(p>0.1)$ if based on peak conductance in the first cycle. Norm., Normalized. ferent combinations of parameter values; for example, the combination of the maximum synaptic amplitudes at ST1 and synaptic tuning profiles at ST2 was referred to as A1T2. As shown in Figure 3, $C$ and $D$ (dashed blue line), applying synaptic amplitudes and tuning profiles at ST1 (A1T1) resulted in $V_{\mathrm{m}}$ responses (measured as peak response of the first cycle) of a relatively flat tuning profile, suggesting that the spiking responses would be very broadly tuned at this stage. Applying synaptic amplitudes and tuning profiles at ST2 (A2T2) resulted in a much sharper $V_{\mathrm{m}}$ response tuning, with an increased response at the optimal orientation and a reduced response at the orthogonal orientation (Fig. 3C,D, solid blue line). This is consistent with the experimental observations that ST1 cells fired more strongly at the orthogonal orientation than ST2 cells, and that the evoked firing rate at the optimal orientation was developmentally increased (Fig. 1D). The developmental sharpening of $V_{\mathrm{m}}$ responses could only be attributed to the increased broadness of the inhibitory tuning, because only increasing synaptic strengths while maintaining the initial tuning profiles (A2T1) resulted in even more reduced selectivity of $V_{\mathrm{m}}$ responses, whereas only increasing the broadness of inhibition while maintaining maximum synaptic amplitudes at ST1 (A1T2) resulted in nearly similarly sharpened $V_{\mathrm{m}}$ responses (Fig. 3C,D, solid and dashed magenta lines, respectively).

To confirm that a sharpening of $V_{\mathrm{m}}$ responses caused by the developmental broadening of inhibitory tuning can occur in real cells, we performed dynamic-clamp recording from layer 4 neurons in vivo (see Materials and Methods). We injected simulated synaptic conductances of different combinations between maximum amplitude and tuning profile, as in the modeling. Consistent with the modeling results, applying ST2 synaptic tuning profiles resulted in a sharper tuning of $V_{\mathrm{m}}$ response, irrespective of which group of synaptic amplitudes were used (Fig. $3 E$, F, solid blue and open magenta symbols). Applying ST1 synaptic tuning profiles resulted in a nearly flat $V_{\mathrm{m}}$ response tuning (Fig. $3 E, F$, open blue and solid magenta symbols), indicating that inhibitory tuning being sharp may be detrimental to the outcome of orientation tuning.

The neuron modeling and dynamic-clamp results predict that $V_{\mathrm{m}}$ response tuning should also be sharpened during development. We examined membrane potential responses in a subset of excitatory cells under current-clamp recording (see Materials and Methods). We found that the tuning of $V_{\mathrm{m}}$ responses at ST2 was significantly sharper than that at ST1 (Fig. 3G,H). On the other hand, biophysical properties, such as resting membrane potential $(-57 \pm 9 \mathrm{mV}$ at ST1, $-59 \pm 12 \mathrm{mV}$ at ST2, mean $\pm \mathrm{SD}$, $n=10$ and 11 , respectively; $p>0.1, t$ test) and spike threshold $(20.3 \pm 4.3 \mathrm{mV}$ above the resting potential at ST1, $20.8 \pm 4.4 \mathrm{mV}$ at ST2; $p>0.1$ ), did not change significantly during the same developmental period. These results, together with the modeling and dynamic-clamp studies, further suggest that the broadening of inhibitory tuning is a major force driving the developmental sharpening of the OS of excitatory neuron responses.

\section{Excitation and inhibition after dark rearing}

Previous studies in ferrets and rats have shown that the maturation of OS is dependent on visual experience (Chapman and Stryker, 1993; Fagiolini et al., 1994; White et al., 2001). However, two recent studies of layer $2 / 3$ of the mouse visual cortex have demonstrated that OS sharpening proceeds rather normally when animals are deprived of visual experience by dark rearing (Kuhlman et al., 2011; Rochefort et al., 2011). Consistent with these recent results, we found that dark rearing starting from P9 did not prevent the normal sharpening of OS in layer 4 excitatory 
A

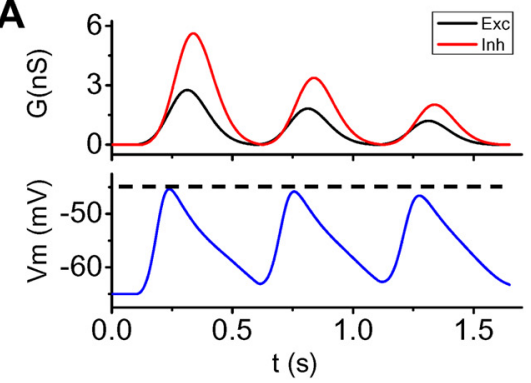

C

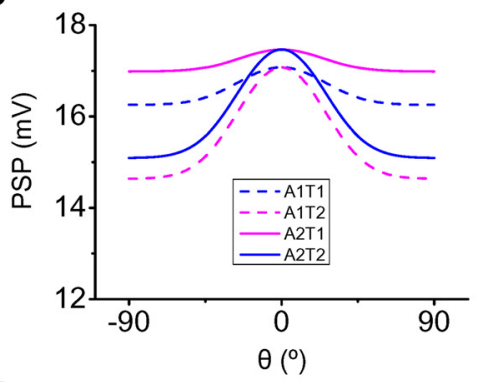

E
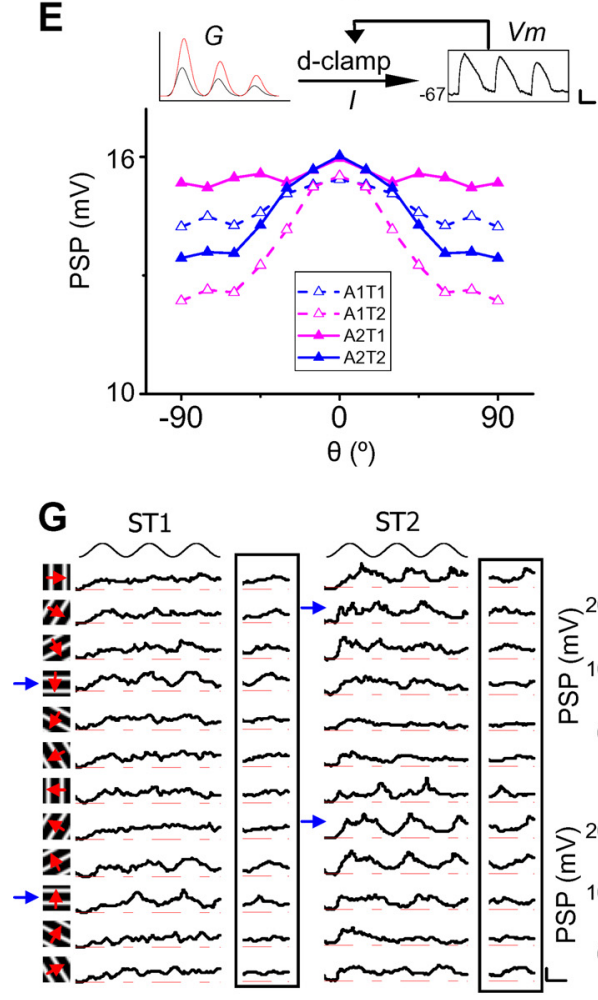

ST2

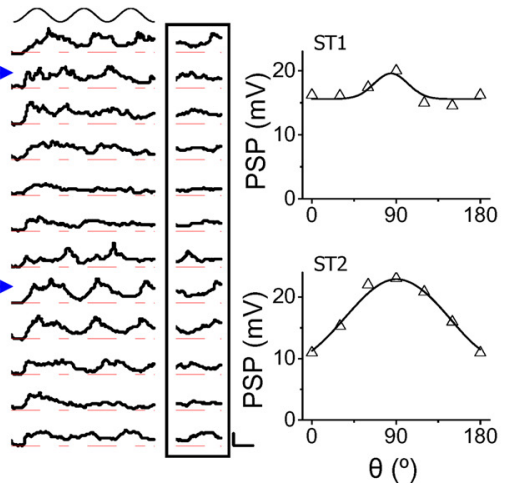

H

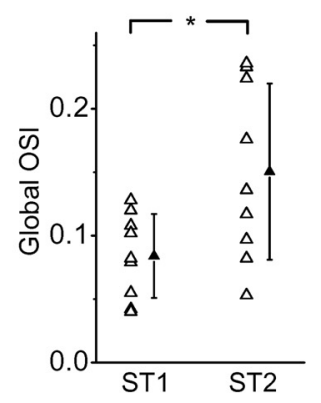

Figure 3. The broadening of inhibitory tuning is a determinant synaptic mechanism underlying the developmental sharpening of OS. $A$, Top, Simulated excitatory (black) and inhibitory (red) synaptic conductances evoked by a drifting grating. Three cycles are shown. Adaptation factor is 0.67 for excitation and 0.57 for inhibition. Bottom, The $V_{\mathrm{m}}$ response generated in the neuron model (solid blue) by integrating the excitatory and inhibitory conductances shown on top. $\boldsymbol{B}$, Orientation tuning curves of excitation (black) and inhibition (red) at ST1 (dash) and ST2 (solid) applied in the model. Tuning curves are based on peak conductance in the first cycle. C, Tuning curves of peak $V_{\mathrm{m}}$ responses (in the first cycle) resulting from different combinations of maximum synaptic amplitude and synaptic tuning profile. A1T2, the combination of excitatory and inhibitory synaptic amplitudes (optimally evoked) at ST1 and tuning profiles at ST2. PSP, Postsynaptic potential. D, Normalized tuning curves of $V_{\mathrm{m}}$ response. $\boldsymbol{E}$, Top, The digital dynamic clamp calculates the current $(I)$ injected into the cell based on the instantaneous $V_{\mathrm{m}}$ and time-dependent synaptic conductances $(G)$. Black and red curves show the time courses of simulated excitatory and inhibitory conductances in an example experiment, respectively. The $V_{\mathrm{m}}$ response is a raw trace from the recorded cell whose resting membrane potential was $-67 \mathrm{mV}$. Calibration: $5 \mathrm{mV}$, $200 \mathrm{~ms}$. Bottom, Tuning curves for recorded peak $V_{\mathrm{m}}$ responses (in the first cycle) in the dynamic-clamp recording of the example cell. $\boldsymbol{F}$, Average normalized tuning curves of $V_{m}$ responses in dynamic-clamp experiments ( $n=4$ cells). Error bars indicate SD. G, Membrane potential responses to gratings of 12 directions in two example cells under current-clamp recording. Boxed are cycle-averaged response waveforms. Calibration: $20 \mathrm{mV}$ left/ $22 \mathrm{mV}$ right, $200 \mathrm{~ms}$. Note that spikes were blocked. $\boldsymbol{H}$, Distribution of global 0 SIs of $V_{\mathrm{m}}$ responses at ST1 and ST2 ( $n=9,9$ cells, respectively). ${ }^{*} p<0.05, t$ test. neurons (Fig. 4A, black). The tuning width of their spiking responses was $28.4 \pm 13.6^{\circ}($ mean $\pm \mathrm{SD})$, which did not differ from $27.2 \pm 17.8^{\circ}$ at normal ST2 $(p>0.1, t$ test). In addition, dark rearing did not prevent the broadening of inhibition either (tuning width was $44.5 \pm 9.5^{\circ}$, which did not differ from that at normal $\mathrm{ST} 2, p>0.1$ ), nor did it have any effect on the excitatory tuning selectivity (Fig. $4 B, C)$. The same conclusion could be reached when peak conductance in the first cycle was measured. In this measure, the global OSI of inhibition was $0.04 \pm$ 0.01 (mean $\pm \mathrm{SD}$ ) under dark rearing, which differed from $0.09 \pm 0.05$ at ST1 $(p<0.01, t$ test $)$, but not from $0.04 \pm 0.02$ at normal ST2. The global OSI of excitation was $0.09 \pm 0.05$ under dark rearing, which did not differ from $0.08 \pm 0.03$ at ST 1 or $0.08 \pm 0.03$ at normal ST2. However, dark rearing did have effects on synaptic strength: it impeded the developmental strengthening of excitation, while the strengthening of inhibition seemed unaffected (Fig. 4D). Based on these results and on our modeling study, we conclude that the apparently "normal" sharpening of OS in dark-reared animals can still be attributed to a broadening of inhibitory tuning, although the underlying synaptic circuits may have been altered by dark rearing.

\section{Development of inhibitory neuron tuning}

The broadening of inhibitory tuning can be attributed to two factors: (1) a broadening of tuning of individual inhibitory neurons; and (2) an increase in the convergence of inhibitory inputs with diverse orientation preference on a common excitatory cell. A recent study in layer $2 / 3$ of mouse visual cortex demonstrated that the orientation tuning of parvalbuminpositive FS neurons is broadened during a similar developmental window (Kuhlman et al., 2011). In layer 4, FS neurons are a predominant source of inhibition, because they account for $50-70 \%$ of inhibitory neurons in this layer (Kawaguchi and Kubota, 1997; Gonchar et al., 2007; Xu et al., 2010). We thus tested whether changes of tuning of this population of inhibitory neurons could contribute to the developmental broadening of inhibitory inputs to excitatory neurons. FS neurons in our loose-patch recordings were identified by their narrow spike waveforms (see Materials and Methods). Consistent with the report in layer $2 / 3$, we found that the tuning selectivity of FS neurons in layer 4 was significantly reduced from ST1 to ST2 
A

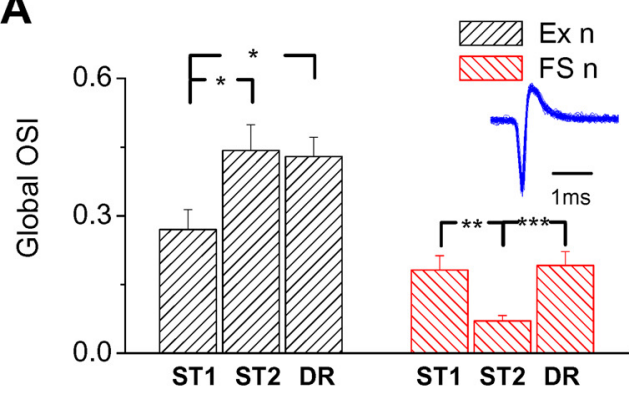

C

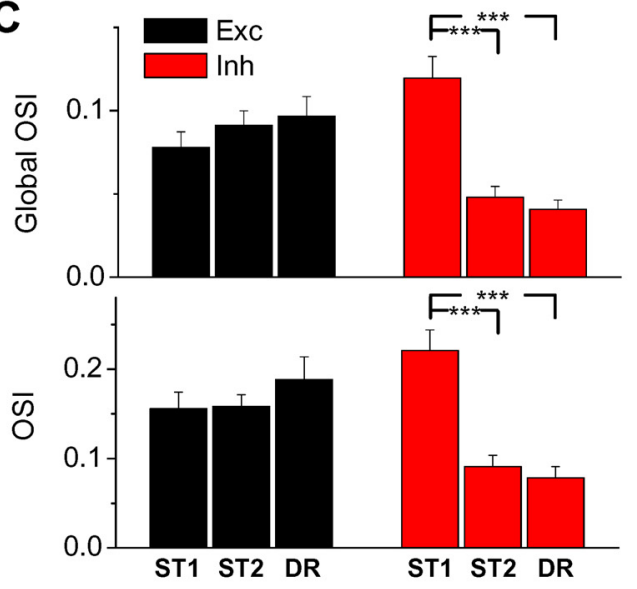

D

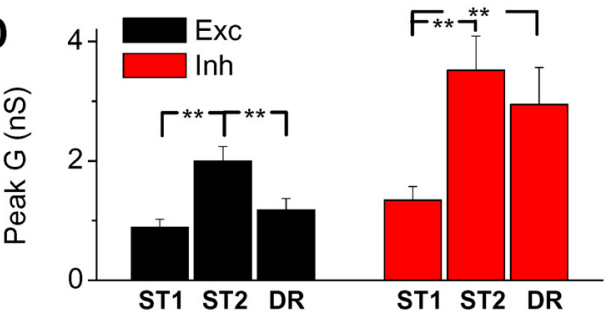

E

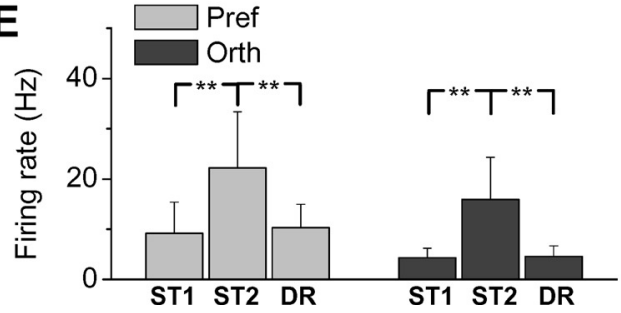

B
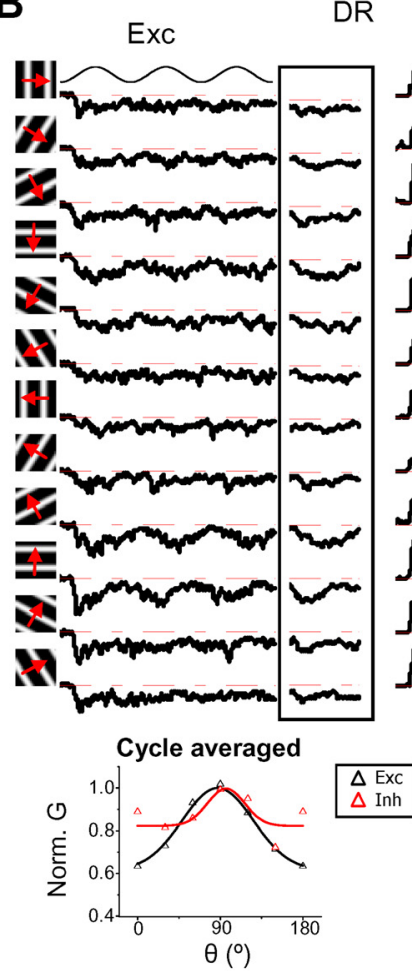

$\mathbf{F}$

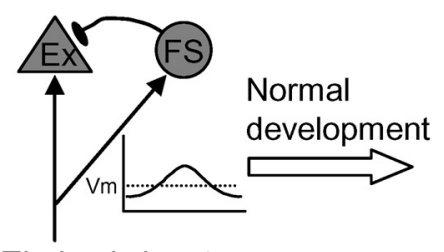

Thalamic input

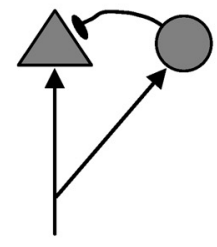

Normal
Inh

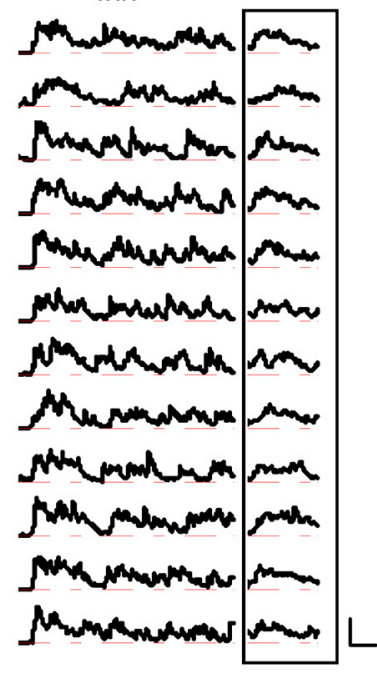

First cycle

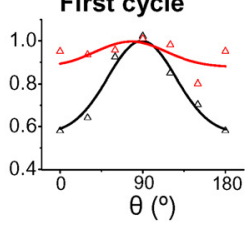

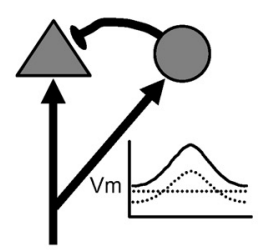

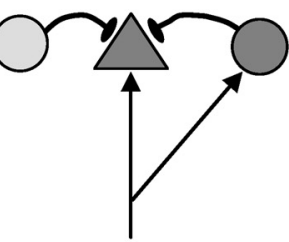

Figure 4. Effects of dark rearing and tuning of inhibitory neurons. A, Average global OSI of spiking responses of excitatory neurons (Ex n; black) and FS inhibitory neurons (FS n; red) at ST1 and ST2 of normal development and under dark rearing (DR, tested at ST2). $N=25,17,21,12,15,13$ from left to right. Error bars indicate SEM. ${ }^{*} p<0.05 ;{ }^{* *} p<0.05 ;{ }^{* * *} p<0.001 ;$ ANOVA with post hoc test. Inset, Example spike waveforms of recorded FS neurons. B, Example excitatory and inhibitory synaptic responses in a dark-reared animal at P25. Calibration: $100 \mathrm{pA}$ (exc)/270 pA (inh), 200 ms. Bottom, Normalized synaptic tuning curves. C, Average global 0SI (top) and global OSI (bottom, see Materials and Methods) for excitation (black) and inhibition (red) at ST1 and ST2 of normal development and under dark rearing. $n=13,14,11$, respectively. Error bars indicate SEM. ${ }^{* * *} p<0.001$, ANOVA with post hoc test. $\boldsymbol{D}$, Average peak conductance of cycle-averaged responses to optimal orientation. ${ }^{* *} p<0.01$, ANOVA with post hoc test. $n=13,14,11$. E, Average firing rate of FS neurons at the preferred and orthogonal orientations. Error bars indicate SD. ${ }^{* *} p<0.01$, ANOVA with post hoc test. $n=12,15,13$. $F$, Proposed circuit models. Top, A simple feedforward circuit can explain the normal development of 0S. FS neurons and their target layer 4 excitatory neuron receive a similar set of thalamic input, thus they exhibit similar preferred orientations. Strengthening of thalamocortical drive onto FS neurons (as indicated by the thickening of arrows) elevates their $V_{m}$ responses, resulting in a broadening of their spiking responses (spike threshold is indicated by a horizontal dotted line). Bottom, Under dark rearing, the thalamocortical drive is not strengthened. The connections from inhibitory neurons preferring other orientations (marked by a different shade, which then receive different sets of thalamic input) are unselectively enhanced.

(Fig. $4 A$, red). Consistently, the tuning width of FS neuron responses was broadened $\left(42.1 \pm 8.5^{\circ}\right.$ at ST1 and $53.4 \pm 16.3^{\circ}$ at $\mathrm{ST} 2$, mean $\pm \mathrm{SD}, p<0.01, t$ test). The evoked firing rate of FS neurons at the preferred orientation was developmentally increased $(9.2 \pm 6.2 \mathrm{~Hz}$ at ST1 vs $22.2 \pm 11.2 \mathrm{~Hz}$ at ST2, $p<0.01)$, similar to excitatory neurons. But unlike excitatory neurons, the firing rate of FS neurons at the orthogonal orientation was increased $(4.2 \pm 2.7 \mathrm{~Hz}$ at ST1 vs $15.9 \pm 8.4 \mathrm{~Hz}$ at ST2, $p<0.01)$
(Fig. 4E). Together, these data demonstrate that a weakening of tuning selectivity of individual inhibitory neurons does contribute to the normal developmental broadening of inhibition.

We also examined tuning of FS neurons in dark-reared animals. As shown in Figure $4 A$, the developmental weakening of orientation tuning of FS neurons was impaired by dark rearing, and they remained as sharply tuned as they were at ST1 (tuning width was $41.3 \pm 9.3^{\circ}$ under dark rearing vs $53.4 \pm 16.3^{\circ}$ at 
normal ST2, $p<0.01)$. In addition, the firing rate of FS neurons was largely reduced by dark rearing (Fig. $4 E$ ). These data indicate that the developmental reduction of FS neuron selectivity depends on visual experience. A similar conclusion has been made for layer 2/3 FS neurons (Kuhlman et al., 2011). Nevertheless, blocking the broadening of output responses of individual inhibitory neurons does not block the broadening of the aggregate inhibitory input to excitatory neurons, indicating that dark rearing may have induced an increase in the convergence of inhibitory neuron inputs with diverse orientation preference. Consistent with this notion, we observed that in dark-reared animals the difference in preferred orientation between excitation and inhibition $\left(\Delta \theta_{\text {pref }}\right)$ was noticeably increased $\left(20.5 \pm 7.9^{\circ}\right.$ for normal ST2 vs $31.5 \pm 28.7^{\circ}$ for dark rearing, mean \pm SD).

\section{Discussion}

Although the developmental maturation of OS has been characterized thoroughly, our understanding of the underlying synaptic mechanisms has lagged behind. To our knowledge, this study is the first to reveal the detailed tuning properties of excitatory and inhibitory synaptic inputs underlying OS in the developing cortex. Contrary to previous thinking, excitatory tuning is not significantly sharpened during a post-eye-opening period, while an inhibitory mechanism, i.e., broadening of the inhibitory tuning and strengthening of inhibitory inputs, primarily accounts for the developmental sharpening of OS. Our results, however, do not rule out the possibility that, before the onset of visual experience, spontaneous activity drives rearrangements of excitatory neuronal connections that mediate an early phase of development of orientation tuning (Miller et al., 1999).

\section{An inhibitory mechanism underlying OS sharpening}

Our results demonstrate that the strength of excitatory synaptic inputs evoked by optimally oriented stimuli is developmentally increased, while the excitatory tuning selectivity remains unchanged. This indicates that excitatory responses to different orientations are scaled up or increased proportionally during development. On a global scale, inhibition is upregulated in a balanced manner, because the ratio between the strengths of optimally evoked excitation and inhibition is relatively constant. Such balanced increase of excitation and inhibition may allow an increased evoked firing rate while preventing response saturations (Turrigiano and Nelson, 2004; Pouille et al., 2009). However, simply scaling up excitation and inhibition without modifying their tuning profiles would result in reduced tuning selectivity, as shown by our modeling and dynamic-clamp results (Fig. 3), which are also consistent with our previous results in the adult cortical study (Liu et al., 2011). Increasing inhibitory input strength together with broadening its tuning profile effectively sharpens orientation tuning by reducing membrane potential responses to nonpreferred stimuli. This result is reminiscent of previous modeling studies of adult visual cortical circuits, which used more broadly tuned inhibitory interactions than excitatory interactions to generate sharp OS in the face of weakly tuned feedforward excitation (Somers et al., 1995; Lauritzen and Miller, 2003). Noticing that the tuning of excitation is considerably weaker in mouse cortical neurons with the response to the orthogonal orientation usually larger than half of that to the optimal orientation (Fig. 2E) (Jia et al., 2010; Liu et al., 2011), the broadening of inhibition is particularly important for achieving sharp OS. Previously, we reported for layer $2 / 3$ simple cells in the adult cortex that inhibition is more broadly tuned than excitation (Liu et al., 2011) (but see Tan et al., 2011). Our present results in layer 4 demonstrate that inhibition becomes more broadly tuned than excitation during development, and that this broadening has important functional significance.

The current results in the V1 appear to differ somewhat from those in the developing primary auditory cortex (A1). In layer 4 of the rat A1, we previously reported that frequency selectivity (as reflected by the half-maximum bandwidth of the frequency tuning curve) of excitation was sharpened after the onset of hearing, while that of inhibition did not change (Sun et al., 2010) (but see Dorrn et al., 2010). Due to the differential changes in excitatory and inhibitory tuning selectivity, eventually in the adult A1 the selectivity of inhibition becomes lower than that of excitation (Sun et al., 2010). The different synaptic mechanisms for the refinement of frequency and orientation tuning, especially a lack of refinement of excitation in the case of orientation tuning, may reflect a difference in neural circuitry underlying these feature selectivities. In the visual system, OS is generated in the cortex and is heavily influenced by synaptic circuitry within the cortex. In the auditory system, frequency selectivity is generated in the periphery and is relayed along the ascending pathways. Sharpening of frequency tuning of neurons at subcortical stages can result in a sharpening of excitatory inputs to cortical neurons. On the other hand, the effect on inhibitory tuning in the A1 is determined by combined changes of tuning of subcortical neurons and that of intracortical inputs. It is also worth noting that orientation tuning properties of synaptic inputs in the mouse layer 4 appear to differ from those of other species such as cat. Inhibition is more broadly tuned than excitation in the mouse layer 4 at more mature stages (but see Tan et al., 2011), whereas in the cat inhibition and excitation have similar tuning widths (Anderson et al., 2000; Mariño et al., 2005). Considering this difference and the fact that the organization of OS in rodents differs from other species (Ohki et al., 2005; Van Hooser et al., 2005; Kerlin et al., 2010; Runyan et al., 2010), how general the developmental synaptic mechanisms revealed in this study are will be an interesting and important issue for future investigations.

\section{Circuit models for the development of OS}

Based on our results on synaptic inputs to excitatory neurons and spiking responses of FS inhibitory neurons, we propose a simple feedforward circuit model that may explain the sharpening of orientation tuning during normal development as well as in darkrearing conditions (Fig. $4 F$ ). In this model, FS neurons providing predominant inhibition onto the layer 4 excitatory neuron receive a similar set of thalamic input as their target, so that inhibition and excitation onto the excitatory neuron have similar preferred orientations. During development, thalamic inputs are strengthened, increasing excitatory drive onto both the FS neurons and the excitatory neuron. Possibly because FS neurons receive less inhibitory control than excitatory neurons (Gabernet et al., 2005), the increased thalamic drive onto FS neurons results in a large increase in their firing rate as well as a broadening of their spiking response tuning attributable to a prominent "iceberg" effect (Somers et al., 1995; Lauritzen and Miller, 2003) and a selectivity blurring effect (Liu et al., 2011) (Fig. 4F, top). The strengthened and broadened inhibition onto the excitatory neuron, on the other hand, can counteract its increased excitatory drive and sharpen its output responses.

On first blush, a broadening of inhibitory tuning does not seem required for the sharpening of OS of excitatory neurons, because dark rearing prevents the broadening of FS neuron responses while the sharpening of excitatory neuron responses is not affected in layer 4 (Fig. $4 A$ ) or in layer $2 / 3$ (Kuhlman et al., 
2011). However, we found that the aggregate inhibitory input still broadened and strengthened in dark-rearing conditions, despite the fact that individual FS inhibitory neurons remained as sharply tuned and weakly responding. This indicates that in dark-rearing conditions, the simple feedforward model is no longer valid, and that additional inhibitory sources must have been recruited. Because previous in vitro studies have shown that depriving visual input induces a marked strengthening of FS neuron to excitatory neuron connections within layer 4 (Maffei et al., 2006), we propose that dark rearing results in a nonselective enhancement of synaptic connections from inhibitory neurons with very different orientation preferences than the excitatory neuron itself (Fig. $4 E$, bottom). This recruitment of other inhibitory neuron sources can lead to the apparently normal strengthening and broadening of inhibition in dark-rearing conditions. Unlike inhibition, dark rearing prevents the developmental strengthening of excitation, which leads to the reduced firing rate of FS neurons. This may suggest that the developmental strengthening of thalamocortical inputs is driven by visual input. More detailed analysis is needed in the future to test these proposed models.

\section{References}

Albus K, Wolf W (1984) Early postnatal development of neuronal function in the kitten's visual cortex: a laminar analysis. J Physiol 348:153-185.

Anderson JS, Carandini M, Ferster D (2000) Orientation tuning of input conductance, excitation, and inhibition in cat primary visual cortex. J Neurophysiol 84:909-926.

Azzalini A (1985) A class of distributions which includes the normal ones. Scand J Statist 12:171-178.

Barlow HB, Pettigrew JD (1971) Lack of specificity of neurones in the visual cortex of young kittens. J Physiol 218:98-100.

Ben-Yishai R, Bar-Or RL, Sompolinsky H (1995) Theory of orientation tuning in visual cortex. Proc Natl Acad Sci U S A 92:3844-3888.

Blakemore C, Van Sluyters RC (1975) Innate and environmental factors in the development of the kitten's visual cortex. J Physiol 248:663-716.

Blue ME, Parnavelas JG (1983) The formation and maturation of synapses in the visual cortex of the rat. II. Quantitative analysis. J Neurocytol 12:697-712.

Buisseret P, Imbert M (1976) Visual cortical cells: their developmental properties in normal and dark-reared kittens. J Physiol 255:511-525.

Chapman B, Stryker MP (1993) Development of orientation selectivity in ferret visual cortex and effects of deprivation. J Neurosci 13:5251-5262.

Chapman B, Stryker MP, Bonhoeffer T (1996) Development of orientation preference maps in ferret primary visual cortex. J Neurosci 16:6443-6453.

Chattopadhyaya B, Di Cristo G, Higashiyama H, Knott GW, Kuhlman SJ, Welker E, Huang ZJ (2004) Experience and activity-dependent maturation of perisomatic GABAergic innervation in primary visual cortex during a postnatal critical period. J Neurosci 24:9598-9611.

Dorrn AL, Yuan K, Barker AJ, Schreiner CE, Froemke RC (2010) Developmental sensory experience balances cortical excitation and inhibition. Nature 465:932-936.

Fagiolini M, Pizzorusso T, Berardi N, Domenici L, Maffei L (1994) Functional postnatal development of the rat primary visual cortex and the role of visual experience: dark rearing and monocular deprivation. Vision Res 34:709-720.

Ferster D, Miller KD (2000) Neural mechanisms of orientation selectivity in the visual cortex. Annu Rev Neurosci 23:441-471.

Frégnac Y, Imbert M (1978) Early development of visual cortical cells in normal and dark-reared kittens: the relationship between orientation selectivity and ocular dominance. J Physiol 278:27-44.

Gabernet L, Jadhav SP, Feldman DE, Carandini M, Scanziani M (2005) Somatosensory integration controlled by dynamic thalamocortical feedforward inhibition. Neuron 48:315-327.

Gödecke I, Kim DS, Bonhoeffer T, Singer W (1997) Development of orientation-preference maps in area 18 of kitten visual cortex. Eur J Neurosci 9:1754-1762.

Gonchar Y, Wang Q, Burkhalter A (2007) Multiple distinct subtypes of GABAergic neurons in mouse visual cortex identified by triple immunostaining. Front Neuroanat 1:3.
Hubel DH, Wiesel TN (1962) Receptive fields, binocular interaction and functional architecture in the cat's visual cortex. J Physiol 160:106-154.

Hubel DH, Wiesel TN (1963) Receptive fields of cells in striate cortex of very young, visually inexperienced kittens. J Neurophysiol 26:994-1002.

Jia H, Rochefort NL, Chen X, Konnerth A (2010) Dendritic organization of sensory input to cortical neurons in vivo. Nature 464:1307-1312.

Kawaguchi Y, Kubota Y (1997) GABAergic cell subtypes and their synaptic connections in rat frontal cortex. Cereb Cortex 7:476-486.

Kayser AS, Miller KD (2002) Opponent inhibition: a developmental model of layer 4 of the neocortical circuit. Neuron 33:131-142.

Kerlin AM, Andermann ML, Berezovskii VK, Reid RC (2010) Broadly tuned response properties of diverse inhibitory neuron subtypes in mouse visual cortex. Neuron 67:858-871.

Kuhlman SJ, Tring E, Trachtenberg JT (2011) Fast-spiking interneurons have an initial orientation bias that is lost with vision. Nat Neurosci 14:1121-1123.

Lauritzen TZ, Miller KD (2003) Different roles for simple-cell and complexcell inhibition in V1. J Neurosci 23:10201-10213.

Liu BH, Li P, Li YT, Sun YJ, Yanagawa Y, Obata K, Zhang LI, Tao HW (2009) Visual receptive field structure of cortical inhibitory neurons revealed by two-photon imaging guided recording. J Neurosci 29:10520-10532.

Liu BH, Li P, Sun YJ, Li YT, Zhang LI, Tao HW (2010) Intervening inhibition underlies simple-cell receptive field structure in visual cortex. Nat Neurosci 13:89-96.

Liu BH, Li YT, Ma WP, Pan CJ, Zhang LI, Tao HW (2011) Broad inhibition sharpens orientation selectivity by expanding input dynamic range in mouse simple cells. Neuron 71:542-554.

Ma WP, Liu BH, Li YT, Huang ZJ, Zhang LI, Tao HW (2010) Visual representations by cortical somatostatin inhibitory neurons-selective but with weak and delayed responses. J Neurosci 30:14371-14379.

Maffei A, Nataraj K, Nelson SB, Turrigiano GG (2006) Potentiation of cortical inhibition by visual deprivation. Nature 443:81-84.

Mangini NJ, Pearlman AL (1980) Laminar distribution of receptive field properties in the primary visual cortex of the mouse. J Comp Neurol 193:203-222.

Mariño J, Schummers J, Lyon DC, Schwabe L, Beck O, Wiesing P, Obermayer K, Sur M (2005) Invariant computations in local cortical networks with balanced excitation and inhibition. Nat Neurosci 8:194-201.

Miller KD (1992) Development of orientation columns via competition between ON- and OFF-center inputs. Neuroreport 3:73-76.

Miller KD (1994) A model for the development of simple cell receptive fields and the ordered arrangement of orientation columns through activitydependent competition between ON- and OFF-center inputs. J Neurosci 14:409-441.

Miller KD, Erwin E, Kayser A (1999) Is the development of orientation selectivity instructed by activity? J Neurobiol 41:44-57.

Miyashita M, Tanaka S (1992) A mathematical model for the selforganization of orientation columns in visual cortex. Neuroreport 3:69-72.

Morales B, Choi SY, Kirkwood A (2002) Dark rearing alters the development of GABAergic transmission in visual cortex. J Neurosci 22:8084-8090.

Nagtegaal AP, Borst JG (2010) In vivo dynamic clamp study of I(h) in the mouse inferior colliculus. J Neurophysiol 104:940-948.

Niell CM, Stryker MP (2008) Highly selective receptive fields in mouse visual cortex. J Neurosci 28:7520-7536.

Ohki K, Chung S, Ch'ng YH, Kara P, Reid RC (2005) Functional imaging with cellular resolution reveals precise micro-architecture in visual cortex. Nature 433:597-603.

Pouille F, Marin-Burgin A, Adesnik H, Atallah BV, Scanziani M (2009) Input normalization by global feedforward inhibition expands cortical dynamic range. Nat Neurosci 12:1577-1585.

Ringach DL, Shapley RM, Hawken MJ (2002) Orientation selectivity in macaque V1: diversity and laminar dependence. J Neurosci 22:5639-5651.

Ringach DL, Hawken MJ, Shapley R (2003) Dynamics of orientation tuning in macaque V1: the role of global and tuned suppression. J Neurophysiol 90:342-352.

Rochefort NL, Narushima M, Grienberger C, Marandi N, Hill DN, Konnerth A (2011) Development of direction selectivity in mouse cortical neurons. Neuron 71:425-432.

Runyan CA, Schummers J, Van Wart A, Kuhlman SJ, Wilson NR, Huang ZJ, Sur M (2010) Response features of parvalbumin-expressing interneu- 
rons suggest precise roles for subtypes of inhibition in visual cortex. Neuron 67:847-857.

Somers DC, Nelson SB, Sur M (1995) An emergent model of orientation selectivity in cat visual cortical simple cells. J Neurosci 15:5448-5465.

Sun YJ, Wu GK, Liu BH, Li P, Zhou M, Xiao Z, Tao HW, Zhang LI (2010) Fine-tuning of pre-balanced excitation and inhibition during auditory cortical development. Nature 465:927-931.

Tan AY, Brown BD, Scholl B, Mohanty D, Priebe NJ (2011) Orientation selectivity of synaptic input to neurons in mouse and cat primary visual cortex. J Neurosci 31:12339-12350.

Tan AY, Zhang LI, Merzenich MM, Schreiner CE (2004) Tone-evoked excitatory and inhibitory synaptic conductances of primary auditory cortex neurons. J Neurophysiol 92:630-643.

Troyer TW, Krukowski AE, Priebe NJ, Miller KD (1998) Contrast-invariant orientation tuning in cat visual cortex: thalamocortical input tuning and correlation-based intracortical connectivity. J Neurosci 18:5908-5927.

Tsumoto T, Suda K (1982) Laminar differences in development of afferent innervation to striate cortex neurones in kittens. Exp Brain Res 45:433-446.

Turrigiano GG, Nelson SB (2004) Homeostatic plasticity in the developing nervous system. Nat Rev Neurosci 5:97-107.
Van Hooser SD, Heimel JA, Chung S, Nelson SB, Toth LJ (2005) Orientation selectivity without orientation maps in visual cortex of a highly visual mammal. J Neurosci 25:19-28.

Wang BS, Sarnaik R, Cang J (2010) Critical period plasticity matches binocular orientation preference in the visual cortex. Neuron 65:246-256.

Wehr M, Zador AM (2003) Balanced inhibition underlies tuning and sharpens spike timing in auditory cortex. Nature 426:442-446.

White LE, Coppola DM, Fitzpatrick D (2001) The contribution of sensory experience to the maturation of orientation selectivity in ferret visual cortex. Nature 411:1049-1052.

Wiesel TN, Hubel DH (1974) Ordered arrangement of orientation columns in monkeys lacking visual experience. J Comp Neurol 158:307-318.

Wu GK, Arbuckle R, Liu BH, Tao HW, Zhang LI (2008) Lateral sharpening of cortical frequency tuning by approximately balanced inhibition. Neuron 58:132-143.

Xu X, Roby KD, Callaway EM (2010) Immunochemical characterization of inhibitory mouse cortical neurons: three chemically distinct classes of inhibitory cells. J Comp Neurol 518:389-404.

Zhang LI, Tan AY, Schreiner CE, Merzenich MM (2003) Topography and synaptic shaping of direction selectivity in auditory cortex. Nature 424:201-205. 